\title{
Aspects of sustainability in new urban developments: case study of Santa Barbara, Seville
}

\author{
M. López de Asiain Alberich, A. Ehrenfried \\ \& M. Sierra Hernández \\ Eddea Arquitectos S.L., Spain
}

\begin{abstract}
The reality of our cities poses new challenges. The proliferation of the sprawling city as a higher standard model is provoking non-sustainable situations in a large number of cities worldwide. The alternative compact city model resulting from the traditional European city provides sustainably advantageous aspects in relation to the spread model, but a specific study is required to determine what aspects of sustainability are applicable to new urban developments in our cities. For this purpose, the case study of the development of Santa Barbara in Seville will be examined, a paradigmatic project for its great size and environmental approach. Covering an overall surface of $3.751 .260 \mathrm{~m}^{2}, 25 \%$ of the area remains as green space, with a built surface of $2.246 .180 \mathrm{~m}^{2}, 81 \%$ of which is devoted to housing and $19 \%$ to business. The topics that have been developed are structured in three large groups: matter, energy and information flows. They have been developed at different scales following a study of accessibility and alternative mobility. The urban space has been shaped according to the interpretation of the green space as a primary consideration, and to the built space as secondary. The project has been developed from the large scale main through routes to small scale pedestrian mobility and access to private and semi-public spaces. Aspects related to energy saving and bioclimatic architecture in buildings have also been developed.

The aim of this study is to take a step forward in urban planning, taking us closer and closer towards the paradigm of sustainability and enabling us to adopt it as a new model for society.

Keywords: environmental architecture, bioclimatic architecture, environmental urban planning, sustainable urban planning, sustainable city.
\end{abstract}




\section{Introduction}

The reality of our cities poses new problems. The proliferation of urban sprawl as a model for higher quality living is provoking unsustainable situations in many cities worldwide. Despite this fact, this model is likely to continue establishing and developing in the current century. As a response to this, the compact city model, derived from the traditional European city, may be a feasible possibility as it promotes aspects of sustainability which have advantages over the spread model. Thus, within the change of paradigm that this shift implies, a specific study has become necessary to determine what changes are applicable to new urban development of our cities.

For this purpose, the study of the development of Santa Barbara in Seville is proposed. This is large size exemplary project - it has an overall surface of $3.751 .260 \mathrm{~m}^{2}$ with a built surface of $2.246 .180 \mathrm{~m}^{2}, 81 \%$ of which is devoted to housing and $19 \%$ to business. Starting from an analysis of the aspects of sustainability that can be developed in this project, specific decisions are taken with regards to urban design.

This study is approached starting from three main points:

- $\quad$ proposal of conceptual guidelines for a sustainable urban design

- description of the main guidelines followed in Santa Barbara urban planning

- analysis of a given design example: sector 1 linear park in Santa Barbara.

\section{Parameters for a sustainable urban design}

According to the sustainability paradigm, an adequate understanding of what a consistent sustainable design should be implies an initial effort that enables us to apply certain issues in the initial design stage of the project. That is, when we face the need to give answers to the demands of society, the city, the individual, nature and the project, the resulting design process should take into account from an early stage the fact that we need to start from some determining factors in order to apply sustainability criteria: human needs (to satisfy comfort and wellbeing demands); the territory and the climate (to adapt better than to transform), human scale; the design of the building (as an answer to the needs); etc. and, above all, the design should control the matter, energy and information flows characteristic of the society in which we live. Therefore the first point we need to take into account when approaching the design of these cities is that sustainability implies the non-existence of unique solutions for different problems. In other words, what is sustainable and ecological in England or Germany may not be sustainable in other countries such as Spain or Portugal.

Another very important question related to design is the fact that transforming the city and consolidating a built environment are not actions indifferent to the context. We cannot expect that any architectural or urban task either rehabilitation or consolidation of a new city - implies no change at all. For this reason, what we can expect and should seek is that this change brings forward certain qualities that are in accordance to sustainability criteria used to 
reduce the impact and negative effects on the land. That is, the conceptualisation of the design should be subject to the idea that the purpose of the project is not only to be built, but it should also locate and integrate the user in the surrounding environment in a way that is consistent with society, human needs and nature. In order to achieve this, controlling matter, energy and information flows (1) in all design aspects proves to be vital. No steps or fragments should be inconsistent. Instead, every element should respond to the function it has been assigned so it consolidates into the integrated whole. Hence the importance of a previous analysis of the project site.

Despite the fact that we are dealing with a completely new city, it is important to point out the fact that we are conceptually creating a city from the perspective of a long historical tradition, that is, under the stare of social and cultural opinion which has forged a precedent of what we call 'the traditional city'.

Winters in Seville are rather warm and short. As opposed to winters, summers carry extreme temperatures that extend practically from mid spring to dates when autumn is well under way. These particular climatic conditions have conditioned the morphology and typologies of the traditional city: narrow streets where the sun does not get in directly during most of the day, light coloured façades - eminently white - to avoid urban heat islands, holes equipped with devices for light control which are not fixed but that can be adjusted depending on the time of the day, patio typologies that allow ventilation and the release of accumulated heat during the night, and other strategies in view of winter such as thermal inertia of walls. On the other hand, it should also be pointed out the fact that the traditional structure constitutes a city that is adapted to human scale in such a way that people can move from one point to another on foot or by bicycle without using fossilized fuels.

Nevertheless, this is not about imitating the traditional city but about extrapolating strategies that have guaranteed its success in the past, as well as trying to solve its problems and adapt it to a modern society.

How do we conceive the modern city? As a city of flows, a city that should be open, adapted to the latest advances and technologies, and at the same time flexible to the forthcoming changes and progress. In the search for sustainability and bioclimatic character, this city should respond to the matter, energy and information flows. While adapting to the shaping process of a new compact city, it proves necessary to tackle three main issues that should be at the centre of the project: the urban green, which structures life and the public space; mobility, with regards to external and internal connections as well as to the proposal of alternative transport systems which minimize the dependency on private vehicles; and use, promoting the mixture and complementarity of uses in space and time, allowing the project to be managed independently to a certain extent with regard to the city and the territory.

\section{Seville Santa Barbara urban proposal}

To build a city that is consistent with the present time means to agree with the sustainability paradigm. A city that is constructed following, as closely as 
possible, some parameters of commitment to the territory, in such a way that we could say that the impact both on the occupied land and on the surroundings is minimal. On the other hand, and, most importantly, this should not imply a decrease in the life quality of the occupants. In order to achieve this, an exhaustive analysis of the resources to be used proves absolutely necessary, as well as determining the criteria according to which these resources can be best managed. Narrowing down to Seville Santa Barbara project [2], the urban design issues developed are the following: urban green, mobility, and uses, which are contextualized in relation to the sun and dominant winds, while some other aspects are developed related to the management of resources - water, energy, refuse - and the consolidation of a social infrastructure.

\subsection{The urban green}

The purpose of this approach is to have vegetation shaping urban space and structuring a new experience towards sustainability and integration with nature and the land, in such a way that users identify the new city as a green habitat in which every place has been provided with content and therefore can be experienced as special and unique. The strategy of relating the urban green to different equipment is used in order to supply content to these spaces, so that we are really speaking about equipped green.

The urban green in Seville Santa Barbara is structured upon three levels.

(1) Mediterranean agricultural green: green as integration of the rural and the urban. A central park linked to the waterway in which native species are predominant.

(2) Public urban green: proper urban green, that is, green space inserted into the urban scheme through public or semi-public parks and walkways, where acclimatized tree species will be the main element shaping corridors and avenues.

(3) Private green: green space inside buildings, that is, private or semi-private gardens consisting of adapted species, as the closest integration unit between the user and nature.

On the other hand, the purpose of the urban green is not only to provide a pleasant public space for walking, sport, leisure or contemplation. It is also a strategy for a bioclimatic design of the city. Vegetation helps reduce the urban heat island effect produced by sun radiation on the pavement and façades, and it also helps control the microclimate of the surrounding area by means of a strategic distribution of water layers, fountains and other devices, thus contributing to the increase of life-quality levels in the area.

\subsection{Mobility}

Urban design assures accessibility of the private vehicle to every point, but minimizing its use. In order to do this, an alternative mobility scheme is established based on the use of public transport - bus, underground and tram and other private means -bicycle and pedestrian transportation. 
With regards to public transport, reservation of space for several underground stations is proposed, as well as the installation of platforms in the main streets to be used for bus or tram networks, so that the maximum distance from a residential area or equipment to a platform is never greater than $500 \mathrm{~m}$.

Urban planning also adapts to personal mobility means, it is designed and measured so that one can go from any residential area to the main nodes covering a very small walking distance $(350 \mathrm{~m})$ or by bicycle $(800 \mathrm{~m})$. In order to achieve this, pedestrian walks and bike lanes are carefully designed, as well as street lines, which should integrate pedestrian and bicycle traffic not as additional requirements but as priorities when it comes to designing an adequate cross section of streets an avenues.

\subsection{Uses}

The criteria of the compact city does not only apply to occupation and construction density, it also implies density of compatible resources in the same space, that is, it pleads for a mixture of uses. An adequate mixture of residential uses with cultural, sports, institutional, commercial and business facilities allows the creation of a centrality, on the one hand, and the possibility that the sector acquires certain independency and self-sufficiency in relation to the rest of the city, on the other. Centrality refers to the act of generating a focus of attraction, whether by means of work, leisure or habitation. It also means creating urban dynamics, making the city alive from the start when diverse types of activities are established, and making it safe for the user in some respect, as the streets will not be empty or unregistered at any time. It also deals with quality of life, as people's minds and psychology are influenced by the dynamics of society.

With regards to independence and self-management capacity, it is a necessary requirement that users find all they need in their everyday life - leisure, work, sport, sight-seeing - in their neighbourhood, so that they do not have to travel to other city sectors in order to find them. This brings about a double advantage: comfort increase, as travelling is not necessary for everyday life, and general improvement of urban quality, as the flow of daily trips from home to work or to shopping areas is reduced.

\subsection{Climatic control}

Sustainability as understood in relation to health and welfare implies the right to enjoy the sun and some fresh air. This is why urban design should take into account factors such as solar radiation and the dominant winds. These issues have been particularly emphasized in Seville Santa Barbara. While taking into account parameters such as the relative position to the sun and the dominant winds to make the most of both forces, these criteria have also a spontaneous controlling effect on comfort factors in buildings as important as lighting, ventilation and air renewal of the interior house and block patios. Thus the structure of the bioclimatic design is defined on the basis of the alignment, the height of the buildings, the volumes, the empty spaces, etc, in such a way that the 
quota of both material and energy resources required is minimized as compared to the quota that would be required if urban design did not provide this advantage.

\subsection{Control and management of resources}

\subsubsection{Water management}

Nowadays, water is a scarce resource we should care for and manage properly, as the city's welfare and health depend upon it. Thus, we consider the treatment of the water cycle as fundamental, not only because of its necessary use in buildings, but also for its use in building processes in general and its link with comfort, with the inhabitant's well-being and with maintenance of the urban green.

Following this line, within an understanding of the water cycle we distinguish the following points:

(1) Its modelling power on the landscape and the environment

(2) Recycling of rainwater

(3) Optimal use of water in domestic processes, so that water used in showers, laundry, etc. (greywater) can be reused.

(4) Consistency of all the aforementioned with drainage and sewerage systems

With regards to point 1 , that is, water as a modeller of landscape, it was established that the main water landmark of the area - even if it was only an artificial irrigation and supply channel - would be the starting point of the general planning scheme. Thus, this channel was given the status of a city river, which constitutes the basis of the surrounding ecosystem. It was not approached as a supply resource but as a landscape and ecologic resource.

With regards to point 2 , an adequate management of the water resources, including recycling of rainwater, is deemed important in view of the size of the area and the large amount of existing green spaces.

The management of water is approached at different levels. At the level of the whole development rainwater is collected into water tanks to be used for irrigation, in case of fire or to supply water features designed in the urban plan such as pods and ornamental fountains.

Additionally, collecting rainwater at the level of building blocks implies storing water in tanks for irrigation of communal gardens.

With regards to water supply and evacuation in the house mentioned in point 3 , measures for saving water are proposed, such as water flow control devices in bathrooms and recycling 'grey' water for toilet tanks, irrigation and fire. The use of these measures will be promoted through regulations.

Finally, regarding sewage and sanity systems, a double network is proposed to separate sewage from rainwater.

\subsubsection{Energy management}

Within sustainable urban planning, the energy question is a key issue: complying with ever increasing comfort and welfare requisites in buildings, minimizing 
consumption, as well as promoting strategies for self-generation and selfmanagement of energy saving. For this reason, we consider an adequate energy management essential in order to comply with the criteria of urban sustainability. This management proposal will extend to all urban scales within the project related to energy production and saving.

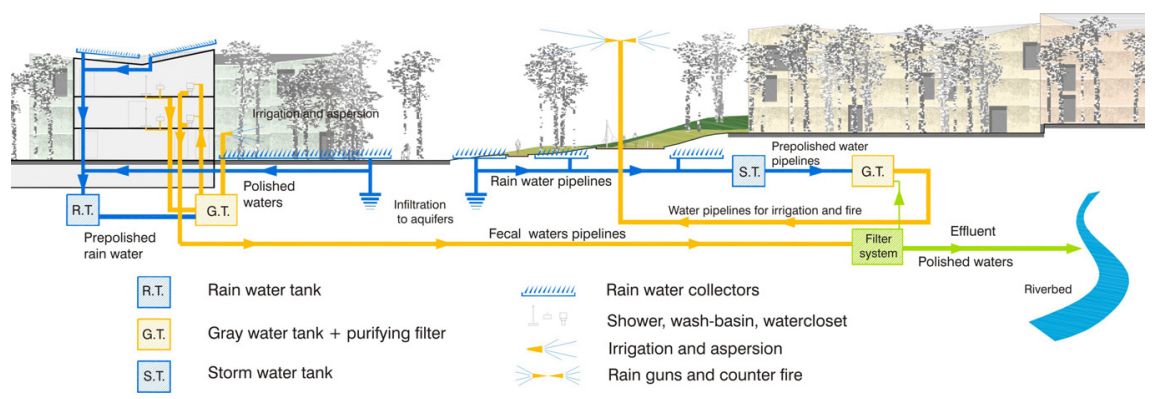

Figure 1: Water management scheme.

3.5.2.1 Production In relation to the question of energy production, three system types are proposed:

1. An energy co-generating system: small stations that produce electricity by using biomass and/or natural gas. The residual heat resulting from it can be used for the setting up of a central heating and air conditioning system for different uses and buildings.

2. Photovoltaic collectors in pergolas - both in private gardens and public spaces - as well as in terrace roofs of public or private buildings (under rental agreements) connected to the main network.

3. Solar collectors in office and residential buildings used both for producing hot water and electricity that will be sold to the main electricity grid.

3.5.2.2 Saving The energy saving question is posed here as a question linked to adequate design which is responsible and coherent. That is, priority is given to the passive over the active. The design should be such that saving occurs spontaneously from the existing qualities, instead of being induced by later operations.

Firstly, we should speak of urban illumination. The choice of lamps and their location should be made according to the criteria of least consumption and citizens' security, using the minimal amount of lamps necessary. Moreover, the choice of lamps should seek to avoid light pollution.

Secondly, avoiding the urban heat island effect as well as thermal inversion is crucial given this latitude and climate. For this reason, the urban planning proposal is designed according to solar radiation and the prevailing winds, as well as to a considerable use of vegetation.

Finally, the main passive saving element proposed is a bioclimatic design of buildings that follows certain environmental and energy saving criteria. The 
purpose of this design pattern are: the use of natural light; an efficient use of artificial light in the buildings; reduction of the need to use heating and air conditioning; use of low consumption appliances, and all kinds of energy saving in general. The criteria for this design pattern will be imposed through regulations.

\subsubsection{Waste management}

The main objective of this chapter is to obtain the minimal amount of waste possible both in the construction phase and during everyday use of inhabitants.

With regards to the construction phase, the soil extracted from excavations and land movements can be reused for the creation of a dynamic landscape in green areas.

As far as building is concerned, regulations will favour the use of recyclable materials and non-polluting, recycled and local materials whenever possible. These materials will be selected not only according to thermal qualities, but also depending on their global behaviour in different construction systems in order to avoid urban heat island effects and thermally unpleasant areas.

Finally, during the construction process a general waste management plan will be carried out to reduce waste during the building period and to allow a selective and centralized collection that is also economic. Regarding the users' daily routine, the question of environmental awareness-raising is as important as the physical act of reducing, recycling and reusing residues. Therefore the facilities promoted have a double target: they are useful in terms of waste management, and on the other hand they encourage participation and commitment on the part of the inhabitant. Within these actions the introduction of "recycling points" can be pointed out. They work as small stations for selective collection of all kinds of refuse including collection of dangerous waste through mobile units that can work locally in all residential areas.

\subsection{Social infrastructure}

When we are faced with the challenge of achieving sustainability, urban conscience-raising and a certain social infrastructure that improves the quality of life becomes absolutely necessary. Some examples are a solar vegetable patch devoted to the dissemination and promotion of renewable energies, soil reserves for compost making as part of logical urban dynamics, numerous tertiary social and cultural facilities; an additional proposal could be the creation of a nature workshop to promote ecological values among the population.

\subsection{Regulations}

Including environmental measures in the local regulations proves to be a fundamental requirement for a sustainable urban design, in order to guarantee consistency among the design stages, the urban planning and the building process. 


\section{Example for public space: sector 01 linear park}

Sector SUO-DE-01 is delineated by two important parallel avenues, which are in turn adjacent to public spaces of great importance: Guadalpark (aquatic park) pine forest, which links this area with the pre-existing urban development; and Santa Barbara main facility area. In this view, the area of the project can be understood as a compact city strip between two large open spaces. Inside this eminently longitudinal strip, we find a series of oblique strips shaped by junctions -both of roads and pedestrian ways alternatively- between the main avenues and the open spaces, and residential areas consisting of tall buildings. It should be pointed out that in the residential islands occupation is not complete, blocks are lined up with the main avenue leaving interior gaps among them. Besides, the shape of these gaps is not regular as the building façades towards them are not parallel. That is, from the urban planning stage some ideas are drawn regarding the longitudinal shape of the structuring space, acting as the dorsal spine of the sector, as a path which is spatially defined by rhythm, but a rhythm with connotations of difference, which provides richness of content and of spatial experience. Within this context, the linear park proposal by Teresa Galí Izard's practice - a landscaping specialist - further increases the spatial differences within the sector, providing each area with its own identity.

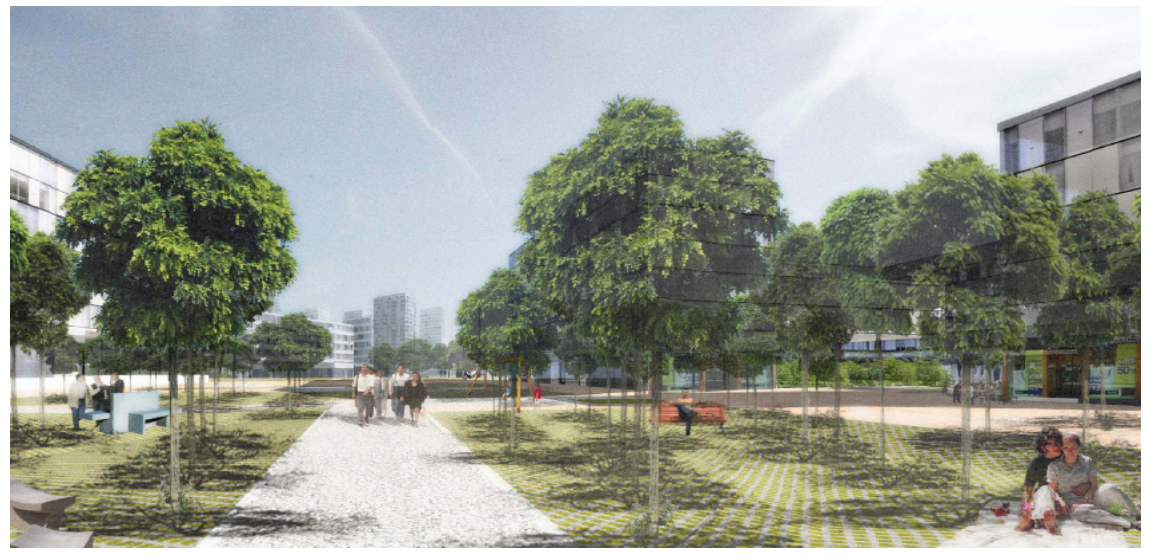

Figure 2: $\quad$ View of Linear Park.

Starting with topography, the proposal is a two meter filling upon the central axis, in cross section, which gradually descends towards the avenues.

Secondly, the scales proposed in the public sphere reinforce this concept. Two different scales are distinguished: that of the neighbourhood in the cross connections that link the avenues delineating the sector, and the intimate scale which is more linked to the specific features of the residential buildings and which can be seen in the gaps between buildings. These differences in scale are echoed in the different approaches used in these areas. In the cross connections spaces more linked to movement - the vegetation used consists of large trees 
with neutral colours and flowers. In the gaps between buildings, however, medium size trees are predominant and are distributed in conglomerate islands over the whole space, each island consisting of a different species with bright colour leaves and flowers.

Thirdly, the spatial differences depend on the different uses and activities happening in the sector. The cross connections, having an open character, provide the setting for occasional massive activities, those which do not have a daily character, namely, temporary facilities such as theatres, open-air cinema, etc. In the gaps between buildings this differentiation becomes more obvious through the pavement, the height and the trees. The pavement makes a difference between uses and activities: sand for children games, mixed pavements under the trees, grass in impassable areas, etc. The question of height refers to tree islands, which are depressed in relation to the rest, so that one has the feeling of entering a different space where one can rest and meditate below the shade of the trees.

The importance of the trees and vegetation should also be pointed out, as they define and organize the areas, activities and scales within the public space of the urban plan. This is the proposal's main value: generating urban ecosystems where the user is just another element that lives and shapes their life-style in relation to the surrounding environment. Not only does vegetation organize the space. It also provides a better environment, contributing to micro-climate control and providing adequate shade. In order to achieve this, special attention has been given to the choice of adequate tree species for each purpose, for example using large trees in the southern façade where the solar radiation is direct.

To sum up, in the development of a lifestyle that is in harmony with the environment, incorporating and adapting nature is a fundamental basis of sustainable urban planning.

\section{References}

[1] Higueras, E. Urbanismo Bioclimático (Bioclimatic Urban Planning) Editorial Gustavo Gili S.L.: Barcelona, 2006.

[2] Estrategia de medio ambiente urbano (Urban Environment Strategy). AL21, Red de Redes de Desarrollo Local Sostenible. Ministerio de Medio Ambiente. 2006.

[3] Lopez de Asiain Alberich, M. La formación medioambiental del arquitecto: hacia un programa de docencia basado en la arquitectura y el medio ambiente. (Environmental Training of Architects: towards a teaching syllabus based on Architecture and the Environment). Doctoral thesis at the Polytechnic University of Catalonia (UPC) within the programme "Energy and Environment Research Fields within Architecture". 2006.

[4] De Cárdenas, J.M., López de Asiain, M., Ehrenfried, A., Olmedo, J., Fernández, P., Barrera, A., Jiménez, B., García, M.A., Solís, R., Cárdenas, J., Romero, D., Romero, A. Urban planning project in Seville Santa Barbara. 2006. 